\title{
Distinctions in Mollicutes Purine Metabolism: Pyrophosphate-Dependent Nucleoside Kinase and Dependence on Guanylate Salvage
}

\author{
VICTOR V. TRYON† AND J. DENNIS POLLACK* \\ Department of Medical Microbiology and Immunology, The Ohio State University, Columbus, Ohio 43210
}

\begin{abstract}
Cell preparations of Acholeplasma florum $\mathrm{L1}^{\mathrm{T}}$, Acholeplasma axanthum $\mathrm{S}_{443^{\mathrm{T}}}$, Acholeplasma granularum BTS-39 ${ }^{\mathrm{T}}$, Spiroplasma floricola 23-6 ${ }^{\mathrm{T}}$, Mycoplasma gallisepticum S6, and Mycoplasma arginini G230 $^{\mathrm{T}}$ were examined for 13 cytoplasmic enzyme activities involved in the salvage and interconversion of nucleobases, nucleosides, and $5^{\prime}$-mononucleotides. The unique pyrophosphate-dependent nucleoside kinase activity known only in Acholeplasma laidlawii B-PG9 was found in A. axanthum and A. granularum. All the organisms could be divided into three groups based upon their patterns of purine salvage and interconversion activities. All the tested organisms, A. laidlawii, and apparently Mycoplasma mycoides subsp. mycoides lack the ability to synthesize guanylates from other purine mononucleotides, indicating that these members of the class Mollicutes can only salvage guanylates. The plant epiphytes $A$. florum and $S$. floricola had an identical purine enzyme pattern which was different from those of all other members of the Mollicutes studied.
\end{abstract}

Mollicutes (mycoplasmas) is a class of procaryotes characterized by lack of a cell wall, complex nutritional requirements, and small genome of generally low guanine-pluscytosine ratio. Nutritional studies on representatives from each of the three families within the class demonstrate the absolute requirement for nucleobases or nucleosides for growth $(3,5,8,11,17-21,23)$. The nutritional requirement for purine precursors suggests the lack of a functional pathway for the de novo synthesis of purines and the dependence on salvage and interconversion enzymes for the biosynthesis of purine nucleotides $(11,24)$. Hamet et al. (6) examined purine salvage but not nucleotide interconversion activity in a number of Mycoplasma species. Only in Mycoplasma mycoides subsp. mycoides $(11,12)$, a species not generally available for study in the United States, and Acholeplasma laidlawii B-PG9 (24) have the pathways involved in purine salvage and interconversion been completely described.

Here we describe our examination of the class Mollicutes for the unique pyrophosphate $\left(\mathrm{PP}_{\mathrm{i}}\right)$-dependent nucleoside kinase activity which is only known in A. laidlawii B-PG9 (24). When first reported, we speculated that the $P_{\mathrm{i}^{-}}$ dependent enzyme activity might prove useful in the study of the phylogenetic relationships of the Mollicutes. We now have studied six other representative Mollicutes for this $\mathrm{PP}_{\mathrm{i}}$-dependent activity and for 12 other cytoplasmic enzyme activities involved in the salvage and interconversion of purine bases, ribonucleosides, and $5^{\prime}$-monophosphates.

\section{MATERIALS AND METHODS}

Organisms. Acholeplasma florum $\mathrm{L1}^{\mathrm{T}}$, Acholeplasma axanthum $\mathrm{S} 743^{\mathrm{T}}$, Acholeplasma granularum BTS-39 ${ }^{\mathrm{T}}$, and Spiroplasma floricola $23-6^{\mathrm{T}}$ were obtained from J. G. Tully, National Institutes of Health, Frederick, Md. Mycoplasma gallisepticum S6 and Mycoplasma arginini $\mathrm{G} 230^{\mathrm{T}}$ were obtained from our stock collection.

Media and growth conditions. All organisms were grown in

\footnotetext{
* Corresponding author.

$\dagger$ Present address: Department of Microbiology, University of Texas Health Sciences Center at San Antonio, San Antonio, TX 78284.
}

our modification of Edward medium (1). Media were supplemented with $2 \%$ (vol/vol) (acholeplasmas) or $5 \%(\mathrm{vol} / \mathrm{vol}$ ) (mycoplasmas and spiroplasma) heat-inactivated horse serum (lot number 200031; KC Biologicals, Lenexa, Kans.). Media for the growth of $M$. arginini were supplemented with $0.3 \%$ (wt/vol) L-arginine hydrochloride (Sigma Chemical Co., St. Louis, Mo.). Organisms were incubated statically at $37^{\circ} \mathrm{C}$ until mid-log phase of growth ( 1 to 3 days). Cells were harvested as previously described $(1,14)$. Cells in dilute $(1: 20)$ buffer (13) were lysed osmotically or sonicated for 1to 30-s pulses (Sonifier Cell Disruptor; Heat Systems, Melville, N.Y.) while on wet ice. Cell extracts were fractionated by centrifugation, dialyzed, and prepared as we described for $A$. laidlawii B-PG9 $(14,24)$. Purity of the fractions was monitored by localization of reduced nicotinamide adenine dinucleotide oxidase $(13,14)$ and adenosine triphosphatase (EC 3.6.1.3) (24) activities.

Assay. The activities of 13 cytoplasmic enzymes involved in the salvage and interconversion of nucleobases, nucleosides, and $5^{\prime}$-mononucleotides were assayed as described for A. laidlawii B-PG9 (24). Briefly, ${ }^{14} \mathrm{C}$-labeled purine substrates were mixed with cofactors at $\mathrm{pH} 7.5$. Dialyzed cell extract containing 20 to $40 \mu \mathrm{g}$ of protein (2) was added to start the reaction. The reaction mixtures were then incubated at $37^{\circ} \mathrm{C}$ with shaking for 4 to $60 \mathrm{~min}$. Incubation times were selected such that greater than $50 \%$ of the starting labeled substrate remained at the end of the reaction period. In preliminary trials, the velocity of each of the reactions was shown to be linear over the prescribed time period and conditions (24). Reactions were terminated by heating at $95^{\circ} \mathrm{C}$ for $2 \mathrm{~min}$. Samples $(20 \mu \mathrm{l})$ of the heated reaction mixtures were spotted onto polyethyleneimine-cellulose plates (Analtech, Inc., Newark, Del.) with $10 \mu \mathrm{g}$ each of nonradioactive standards $(24) .{ }^{14} \mathrm{C}$-labeled substrate and product were separated by thin-layer chromatography in polar solvents $(17,24)$. Resolved purines were visualized by ultraviolet light, scraped into counting fluid, and assayed for radioactivity. In all cases, greater than $90 \%$ of the applied label was recovered from substrate and product spots. During initial experiments, all plates were autoradiographed after chromatography to help exclude the presence of competing reactions. Radioisotope data were corrected for 
TABLE 1. Enzyme activity

\begin{tabular}{|c|c|c|c|c|c|c|c|}
\hline \multirow{2}{*}{ Enzyme and substrate } & \multicolumn{7}{|c|}{ Enzyme activity in: } \\
\hline & A. laidlawii B & A. axanthum & A. granularum & A. florum & S. floricola & M. gallisepticum & $M$. arginini \\
\hline \multicolumn{8}{|l|}{ Phosphoribosyltransferases } \\
\hline ADE & $5.08(1.45)$ & $6.09(1.31)$ & $8.34(1.95)$ & $47.0(3.84)$ & $16.1(1.79)$ & $1.18(0.309)$ & $10.7(0.324)$ \\
\hline GUA & $2.76(1.66)$ & $9.57(0.770)$ & $4.66(0.512)$ & $2.64(0.614)$ & $16.3(0.923)$ & $18.3(2.36)$ & $2.11(0.096)$ \\
\hline HX & $3.69(2.11)$ & $6.66(0.998)$ & $2.49(0.458)$ & $2.55(0.331)$ & $6.03(1.95)$ & $7.16(1.06)$ & $2.97(0.014)$ \\
\hline $\mathrm{X}$ & $0.08(0.02)$ & $\mathrm{NA}^{b}$ & NA & NA & NA & NA & NA \\
\hline \multicolumn{8}{|l|}{ Nucleoside phosphorylases } \\
\hline ADO & $1.97(0.62)$ & $2.97(0.070)$ & $0.445(0.028)$ & $1.90(0.271)$ & $3.41(0.430)$ & $1.01(0.171)$ & $2.48(0.186)$ \\
\hline GUO & $1.30(0.27)$ & $1.27(0.045)$ & $0.135(0.009)$ & $4.93(0.289)$ & $3.15(0.455)$ & $0.663(0.101)$ & $5.88(1.06)$ \\
\hline INO & $1.30(0.49)$ & $1.11(0.070)$ & $0.639(0.115)$ & $2.19(0.462)$ & $3.93(0.750)$ & $0.565(0.257)$ & $1.65(0.121)$ \\
\hline $\mathrm{XO}^{c}$ & $0.009(0.003)$ & NA & NA & NA & NA & NA & NA \\
\hline \multicolumn{8}{|l|}{ Nucleoside phosphorylases } \\
\hline $\mathrm{ADE}$ & $7.12(3.54)$ & $11.5(0.044)$ & $11.1(1.36)$ & $93.6(8.68)$ & $26.5(4.58)$ & $18.7(2.69)$ & $15.6(1.03)$ \\
\hline GUA & $13.2(4.13)$ & $10.1(1.73)$ & $17.0(1.30)$ & $17.7(2.70)$ & $37.8(7.58)$ & $14.9(4.43)$ & $9.74(1.20)$ \\
\hline $\mathrm{HX}$ & $7.56(1.89)$ & $6.35(0.473)$ & $6.07(0.0119)$ & $4.24(1.05)$ & $14.3(0.318)$ & $3.49(0.802)$ & $3.39(0.215)$ \\
\hline $\mathrm{X}$ & $0.034(0.007)$ & NA & $0.012(0.002)$ & NA & $0.645(0.057)$ & NA & NA \\
\hline \multicolumn{8}{|l|}{$\mathrm{PP}_{\mathrm{i}}$-nucleoside kinases } \\
\hline ADO & $58.9(21.3)$ & $0.529(0.160)$ & $0.161(0.012)$ & NA & NA & NA & NA \\
\hline GUO & $50.8(21.3)$ & $0.291(0.080)$ & NA & NA & NA & NA & NA \\
\hline INO & $32.3(8.68)$ & NA & NA & NA & NA & NA & NA \\
\hline XO & NA & NA & NA & NA & NA & NA & NA \\
\hline \multicolumn{8}{|l|}{$5^{\prime}$-Nucleotidases } \\
\hline AMP & $12.8(2.76)$ & $0.810(0.163)$ & $0.039(0.002)$ & NA & NA & $0.064(0.009)$ & NA \\
\hline GMP & $0.15(0.020)$ & $0.068(0.001)$ & $0.010(0.001)$ & NA & NA & NA & NA \\
\hline IMP & $1.82(0.120)$ & $0.064(0.015)$ & $0.022(0.002)$ & NA & NA & NA & NA \\
\hline XMP & $0.003(0.001)$ & NA & NA & NA & NA & NA & NA \\
\hline $\begin{array}{l}\text { Adenylosuccinate } \\
\text { synthetase and lysase }\end{array}$ & $0.524(0.184)$ & $0.210(0.010)$ & $0.035(0.005)$ & NA & NA & $0.108(0.027)$ & $0.145(0.01)$ \\
\hline GMP reductase & $0.642(0.301)$ & $0.050(0.003)$ & $0.008(0.001)$ & $0.003(0.001)$ & $0.037(0.005)$ & NA & NA \\
\hline GMP synthetase & NA & NA & NA & $\mathrm{NT}^{d}$ & $0.005(0.001)$ & NA & NA \\
\hline IMP dehydrogenase & NA & NA & NA & NA & NA & NA & NA \\
\hline $\begin{array}{l}\text { Adenylate deaminases } \\
\text { (AMP, ADO, ADE) }\end{array}$ & NA & NA & NA & NA & NA & NA & NA \\
\hline
\end{tabular}

${ }^{a}$ Values are given in nanomoles of product synthesized per minute per milligram of protein ( \pm standard deviation). The number of different cell batches studied is three except for $A$. laidlawii $\mathrm{B}$. The data listed for A. laidlawii B are our previous results (24).

${ }^{b}$ NA, No activity detected $\left(<0.003 \mathrm{nmol}\right.$ of product synthesized $\mathrm{min}^{-1} \mathrm{mg}^{-1}$ of protein) in extracts from each of three or more different batches of cells.

¿ XO, Xanthosine.

${ }^{d}$ NT, Not tested.

quenching and calculated as disintegrations per minute and then converted to nanomoles of product synthesized per minute per milligram of protein by calculation with the specific activity of the labeled substrate.

\section{RESULTS}

The various members of the Mollicutes were tested for activities associated with the salvage and interconversion of purine bases, ribonucleosides, and ribomononucleotides. Three to seven different batches of each organism were assayed. Enzyme activities are reported as nanomoles of product per minute per milligram of protein (Table 1). Enzyme activities were considered positive when the rate of product synthesized exceeded $0.003 \mathrm{nmol} \mathrm{min} \mathrm{mg}^{-1}$ of protein. The relationship of the various enzymes involved in purine salvage and interconversion is shown in Fig. 1A and $\mathrm{B}$. The novel $\mathrm{PP}_{\mathrm{i}}$-dependent purine nucleoside kinase activity found in A. laidlawii B (24) was detected in A. axanthum for adenosine (ADO) and guanosine (GUO) and in $A$. granularum for ADO. No $\mathrm{PP}_{\mathrm{i}}$-dependent xanthosine nucleoside kinase activity or adenosine $5^{\prime}$-triphosphate (ATP)dependent ADO, inosine (INO), or GUO kinase activity (adenosine kinase [EC 2.7.1.20] and inosine kinase [EC 2.7.1.73]) was detected in any organism. Phosphoribosyltransferase activity (adenine [EC 2.4.2.7] and hypoxanthine [EC 2.4.2.8]) for the substrates adenine (ADE), guanine (GUA), and hypoxanthine (HX) were found in all the organisms. Phosphoribosyltransferase activity for xanthine (X) was not detected in any organism in this study but was detected previously in A. laidlawii B (24). Nucleoside phosphorylase activity (purine-nucleoside phosphorylase [EC 2.4.2.1]) in the direction of the nucleobase with ADO, INO, and GUO or in the opposite direction toward the nucleoside with ADE, HX, or GUA was found in all organisms. In $A$. granularum we also detected nucleoside phosphorylase activity for $X$. Cytoplasmic 5 '-nucleotidase (EC 3.1.3.5) activity for adenosine 5'-monophosphate (AMP), guanosine 5'-monophosphate (GMP), and inosine 5'monophosphate (IMP) was detected in $A$. axanthum and $A$. granularum. No cytoplasmic 5 '-nucleotidase activity was detected in S. floricola or A. florum or either Mycoplasma species. Adenylosuccinate synthetase (EC 6.3.4.4) and adenylosuccinate lyase (EC 4.3.2.2) were detected in all organisms except $S$. floricola and $A$. florum. GMP reductase activity (EC 1.6.6.8) was found in the acholeplasmas and the spiroplasma but not in the two Mycoplasma species. GMP synthetase activity (EC 6.3.4.1) was detected only in $S$. floricola. IMP dehydrogenase (EC 1.2.1.14), AMP deaminase (EC 3.5.4.6), adenosine deaminase (EC 3.5.4.4), and adenine deaminase (EC 3.5.4.2) activities were not detected in any organism. Enzyme activity for these latter four enzymes was detected in Echerichia coli ATCC 25922 , 

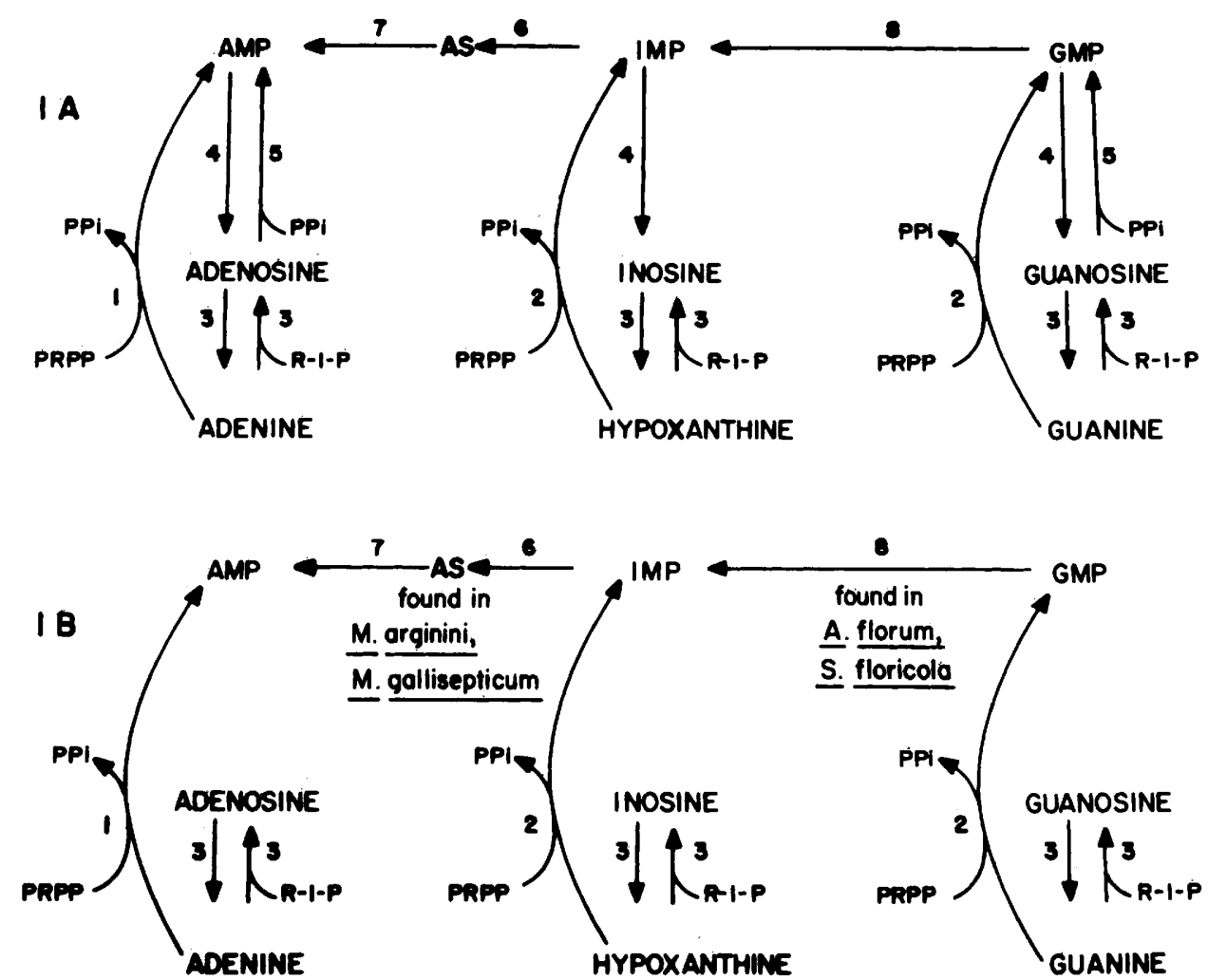

FIG. 1. Schematic diagram of the proposed purine salvage pathways in six members of Mollicutes. The data are all taken from Table 1. Abbreviations: 1, adenine phosphoribosyltransferase; 2, hypoxanthine-guanine phosphoribosyltransferase; 3 , purine nucleoside phosphorylase; 4, 5'-nucleotidase; 5 , $\mathrm{PP}_{i}$-dependent nucleoside kinase; 6 , adenylosuccinate synthetase; 7, adenylosuccinate lyase; 8 , GMP reductase; PRPP, phosphoribosyl pyrophosphate; R-1-P, ribose-1-phosphate; and AS, adenylsuccinate. (A) A. granularum and A. axanthum. In panel $\mathrm{A}, \mathrm{PP}_{\mathrm{i}}$-guanosine nucleoside kinase activity $\left(\mathrm{PP}_{\mathrm{i}}\right.$-dependent rucleoside kinase) was found only in $A$. axanthum. Not included in panel $\mathrm{A}$ is the observation that $A$. granularum had xanthine phosphorylase activity and $S$. floricola had GMP synthetase activity. (B) $A$. florum, $S$. floricola, $M$. arginini, and $M$. gallisepticum. Panel B shows that only $M$. arginini and $M$. gallisepticum have enzyme activities for adenylosuccinate synthetase and adenylosuccinate lyase, while only $A$. florum and $S$. floricola have enzyme activity for GMP reductase.

Bacillus subtilis (60015) (24), or human erythrocytes and lymphocytes (data not shown) (24).

\section{DISCUSSION}

We found the novel $\mathrm{PP}_{\mathrm{i}}$-dependent nucleoside kinase activity described in A. laidlawii B-PG9 (24) in A. axanthum and $A$. granularum but not in $A$ florum. Similarly, we detected the cytoplasmic $5^{\prime}$-nucleotidase activity reported in A. laidlawii B-PG9 (24) in A. axanthum and A. granularum but not in $A$. florum. The lack of similarity between $A$. florum and the other acholeplasmas was not surprising since (i) A. florum shows little homology with other acholeplasmas or mycoplasmas when examined by nucleic acid hybridization (22); (ii) it is also relatively unrelated to other Acholeplasma species, as judged by growth inhibition and plate immunofluorescence studies (22); (iii) unlike other acholeplasmas, it synthesizes little lipid from acetate (15); and (iv) unlike other acholeplasmas, it has significant levels of reduced nicotinamide adenine dinucleotide oxidase activity localized in the cytoplasm (J. D. Pollack, K. D. Beaman, and V. V. Tryon, Abstr. Meet. Int. Organ. Mycoplasmol. 1982, Yale J. Biol. Med. 57:891). The findings of $\mathrm{PP}_{\mathrm{i}^{-}}$ dependent nucleoside kinase and 5 '-nucleotidase activity in the cytoplasm of three of four acholeplasmas, including $A$. laidlawii B-PG9 (24) but not $A$. florum, suggests that these activities may be common to other Acholeplasma species and that further study of $A$. florum and other plant isolates and their taxonomic relationship to other acholeplasmas is warranted.

Most striking in the examination of the purine salvage and interconversion enzyme activities of Acholeplasma, Mycoplasma, and Spiroplasma species is the lack of enzyme activities necessary for the synthesis of guanylates from other purine mononucleotides. In the organisms tested here, and as has been reported for $M$. mycoides subsp. mycoides $(11,12)$, no activity was found for AMP deaminase or IMP dehydrogenase. AMP deaminase permits the conversion of AMP to IMP, and IMP dehydrogenase permits the conversion of IMP to xanthosine $5^{\prime}$-monophosphate (XMP). XMP is converted by GMP synthetase to GMP. Only $S$. floricola exhibited GMP synthetase activity, although as indicated above, like every other member of Mollicutes studied, it lacked IMP dehydrogenase activity. Therefore, some members of Mollicutes studied can convert guanylates to inosinates, but none of the six studied can apparently convert adenylates to inosinates or inosinates to guanylates. These six members of Mollicutes and A. laidlawii B-PG9 may only be able to salvage guanylates.

The organisms we studied are divided into three groups based on their respective patterns of purine salvage and interconversion enzyme activities in cytoplasmic fractions. All the acholeplasmas tested except for A. florum had some $\mathrm{PP}_{\mathrm{i}}$-dependent nucleoside kinase activity and cytoplasmic 5 -nucleotidase activity. The features of this pattern are shown in Fig. $1 \mathrm{~A}$ and are very similar to those already 
published for A. laidlawii B-PG9 (24). The main difference is the ability of $A$. laidlawii B-PG9 to interconvert xanthylates (24). A second pattern of purine salvage was displayed by $A$. florum and $S$. floricola (Fig. 1B). A. florum, which was isolated from the surfaces of plants (9), had a purine enzyme pattern identical to that of $S$. floricola, another plant epiphyte but included in the family Spiroplasmatales (4). Like the acholeplasmas studied, both $A$. florum and $S$. floricola could convert GMP to IMP. Like the two Mycoplasma species, each lacked purine nucleoside kinase and 5'nucleotidase activity. The absence of these two latter activities indicates that the flow of carbon is towards GMP via the guanine phosphoribosyltransferase reaction which requires phosphoribosylpyrophosphate. This hypothesis emphasizes the role of phosphoribosylpyrophosphate in Mollicutes purine metabolism (16).

$M$. arginini and $M$. gallisepticum exhibited a third pattern of purine salvage which was very similar to that for A. florum and S. floricola (Fig. 1B). The two Mycoplasma species had adenylosuccinate synthetase and lyase activities but no GMP reductase activity. The converse was true for $A$. florum and $S$. floricola.

Our inability to detect enzyme activity does not necessarily mean that these enzymes are inactive or absent in the intact organism. During lysis and subsequent fractionation, enzyme activity may be lost or our assays may lack some necessary cofactor or condition. However, our data are consistent with the whole cell-labeling experiments of McIvor and Kenny (10) and Mitchell and Finch (11) and with most of the known nutritional requirements of these organisms.

Enzyme activities are reported here as rates; however, such values may be in error, since our assays were conducted with crude cell extracts, and there may be competing reactions. We minimized competing reactions by extensive dialysis of our cell-free preparations and adjustment of the reaction times (24). In the case of IMP dehydrogenase activity, we recovered at least $97 \%$ of the radioactivity as unreacted IMP; that is, there were no competing reactions. Therefore, our failure to detect IMP dehydrogenase activity was not due to the conversion of XMP, the product of the reaction, to other compounds or back to IMP since there is no known back reaction. When testing was possible, control reactions lacking required cofactors also showed complete recovery of substrate. We used $E$. coli as our positive control for IMP dehydrogenase activity (24).

No ATP-dependent purine nucleoside kinase activity was detected in any member of Mollicutes. To determine whether the lack of ATP-dependent activity was due to contaminating membrane adenosine triphosphatase activity, dialyzed cell extract was examined for adenosine triphos phatase activity. Under conditions described for the assay of A. laidlawii B-PG9 (24) purine nucleoside kinase activity, greater than $90 \%$ of the radiolabeled ATP remained after the incubation period (data not shown). This indicates that our inability to detect ATP-dependent purine nucleoside kinase activity was not due to the loss of ATP in the reaction mixtures as a result of contaminating membrane adenosine triphosphatase activity.

This is the first report suggesting the dependence of members of the Mollicutes on guanine phosphoribosyltransferase activity. Since IMP dehydrogenase activity is apparently absent in all members of the Mollicutes tested, we conclude that the class Mollicutes cannot synthesize guanine monophosphate from other purine mononucleotides. These organisms are, therefore, dependent on
$\mathrm{PP}_{\mathrm{i}}$-dependent guanosine kinase and guanine phosphoribosyltransferase (in some species only the latter) for the biosynthesis of GMP. Although we cannot yet draw too broad a generalization, the data from the seven members of the Mollicutes we examined suggest that guanine phosphoribosyltransferase and possibly $\mathrm{PP}_{\mathrm{i}}$-dependent guanosine kinase are essential Mollicutes enzymes and promising loci for biochemical inhibition which may alter infection, pathogenesis, or pathology caused by members of the Mollicutes, for example, in the avian pathogen $M$. gallisepticum. The swine pathogen Mycoplasma hyopneumoniae $\mathbf{J}$, although not studied extensively, lacks IMP dehydrogenase activity ( $\leq 3$ pmol of XMP synthesized $\mathrm{min}^{-1} \mathrm{mg}^{-1}$ ) in each of three different cell batches (J. D. Pollack, unpublished data) and may be dependent on guanylate salvage and guanine phosphoribosyltransferase activity. Similarly, M. mycoides subsp. mycoides also lacks IMP dehydrogenase activity and may be dependent on guanylate salvage and guanine phosphoribosyltransferase activity (11). Inhibitors of guanine phosphoribosyltransferase activity have been described, but nonspecific effects have made them unsuitable for use in vivo in humans (7). Perhaps if our observations are more widespread amongst the members of the Mollicutes, these inhibitors may have the potential for use in the treatment of Mollicutes infections in animals, cell cultures, or perhaps plants.

\section{ACKNOWLEDGMENTS}

We thank Earl E. Ose and Eli Lilly \& Co. for their support in our studies of $M$. hyopneumoniae and M. V. Williams for valuable advice.

\section{LITERATURE CITED}

1. Beaman, K. D., and J. D. Pollack. 1981. Adenylate energy charge in Acholeplasma laidlawii. J. Bacteriol. 146:1055-1058.

2. Bradford, M. M. 1976. A rapid and sensitive method for the quantitation of microgram quantities of protein utilizing the principle of protein-dye binding. Anal. Biochem. 72:248-254.

3. Chang, C. J., and T. A. Chen. 1982. Spiroplasmas: cultivation in chemically defined medium. Science 215:1121-1122.

4. Davis, R. E., I.-M. Lee, and J. F. Worley. 1981. Spiroplasma floricola, a new species isolated from surfaces of the tulip tree, Liriodendron tulipifera L. Int. J. Syst. Bacteriol. 31:456-464.

5. Greenaway, S. D., and D. A. J. Wase. 1982. Two chemically defined media for the growth of Acholeplasma laidlawii A. Biotechnol. Lett. 4:217-222.

6. Hamet, H., C. Bonissol, and P. Carter. 1980. Enzymatic activities on purine and pyrimidine metabolism in nine mycoplasma species contaminating cell cultures. Clin. Chim. Acta 103:15-22.

7. Johnson, L. A., R. B. Gordon, and B. T. Emmerson. 1979. Inactivation of hypoxanthine guanine phosphoribosyltransferase by guanosine dialdehyde: an active site directed inhibitor. Biochem. Med. 22:33-42.

8. Liska, B., and P. F. Smith. 1974. Requirements of Acholeplasma laidlawii A, strain LA 1, for nucleic acid precursors. Folia Microbiol. 19:107-117.

9. McCoy, R. E., H. G. Basham, J. G. Tully, D. L. Rose, P. Carle, and J. M. Bové. 1983. Acholeplasma florum, a new species isolated from plants. Int. J. Syst. Bacteriol. 34:11-15.

10. McIvor, R. S., and G. E. Kenny. 1978. Differences in incorporation of nucleic acid bases and nucleosides by various Mycoplasma and Acholeplasma species. J. Bacteriol. 135:483-489.

11. Mitchell, A., and L. R. Finch. 1977. Pathways of nucleotide biosynthesis in Mycoplasma mycoides subsp. mycoides. J. Bacteriol. 130:1047-1054.

12. Mitchell, A., I. L. Sin, and L. R. Finch. 1978. Enzymes of purine metabolism in Mycoplasma mycoides subsp. mycoides. J. Bacteriol. 134:706-712. 
13. Pollack, J. D. 1975. Localization of reduced nicotinamide adenine dinucleotide oxidase activity in Acholeplasma and Mycoplasma. Int. J. Syst. Bacteriol. 25:108-113.

14. Pollack, J. D. 1983. Localization of enzymes in mycoplasmas: preparatory steps. Methods Mycoplasmol. 1:327-332.

15. Pollack, J. D., K. D. Beaman, and J. A. Robertson. 1984. Synthesis of lipids from acetate is not characteristic of Acholeplasma or Ureaplasma species. Int. J. Syst. Bacteriol. 34:124-126.

16. Pollack, J. D., V. V. Tryon, and K. D. Beaman. 1983. The metabolic pathways of Acholeplasma and Mycoplasma: an overview. Yale J. Biol. Med. 56:709-716.

17. Randerath, K., and E. Randerath. 1964. Ion-exchange chromatography of nucleotides on poly-(ethyleneimine)-cellulose thin layers. J. Chromatogr. 16:111-125.

18. Razin, S. 1962. Nucleic acid precursor requirement of Mycoplasma laidlawii. J. Gen. Microbiol. 28:243-250.

19. Razin, S., and A. Cohen. 1963. Nutritional requirements and metabolism of Mycoplasma laidlawii. J. Gen. Microbiol. 30:141-154.

20. Rodwell, A. W. 1967. The nutrition and metabolism of mycoplasma: progress and problems. Ann. N.Y. Acad. Sci. 143:88-109.

21. Smith, D. W., and P. C. Hanawalt. 1968. Macromolecular synthesis and thymineless death in Mycoplasma laidlawii B. J. Bacteriol. 96:2066-2076.

22. Stephens, E. B., G. S. Aulakh, R. E. McCoy, D. L. Rose, J. G. Tully, and M. F. Barile. 1981. Lack of genetic relatedness among animal and plant acholeplasmas by nucleic acid hybridization. Curr. Microbiol. 5:367-370.

23. Tourtellotte, M. E., H. J. Morowitz, and P. Kasimer. 1961. Defined medium for Mycoplasma laidlawii. J. Bacteriol. 88:11-15.

24. Tryon, V. V., and J. D. Pollack. 1984. Purine metabolism in Acholeplasma laidlawii $\mathrm{B}$ : novel $\mathrm{PP}_{\mathrm{i}}$-dependent nucleoside kinase activity. J. Bacteriol. 159:265-270. 